\title{
Early-Fatherhood in White City, Jabavu, Soweto: A Time-Bound, Contextual Construct
}

\author{
Naledi Selebano and Grace Khunou*
}

\author{
University of Johannesburg, Kingsway and University Rds, Auckland Park, South Africa
}

\begin{abstract}
While young mothers have enjoyed the interests of researchers and policy makers, young fathers' experiences have only been examined recently. Through a thematic content analysis of interviews with six black young fathers from White City, Jabavu in Soweto, this article argues that early fatherhood should be understood through an examination of how it is lived in the social, political, cultural and economic contexts of particular communities. The data from this study indicate that there are strong ties between the young men's experiences and the overall community values, history and culture where they experience fatherhood. The article concludes that for appropriate policies and strategies to be implemented where young fathers are concerned, more context specific research should be conducted.
\end{abstract}

Keywords: Early fatherhood, socio-economic context, White City Jabavu, young fathers' experiences.

\section{INTRODUCTION}

When public discourse and research refer to teenage pregnancy and early-parenthood, the dialogue typically focuses on young women [1]. The South African Department of Education's most recent analysis of teenage pregnancy examined teenage fathers and their attitudes towards early fatherhood [2]. The report indicates that the risk factors associated with teenage pregnancy for young women are similarly applicable to young men [2]. Findings [3] indicate the significant gap posed by the lack of research on young fathers as they face many negative educational, financial, social, health and other developmental consequences. The high teenage pregnancy rate and the high number of illegal abortions done out of fear by young girls clearly indicate that more interventions must take place for young men [4]. Such interventions will allow for more support from young men facing the possibility of early-fatherhood.

Interventions for young fathers will also begin to address the negative experiences [5] associated with earlyfatherhood. Even though this negativity led to a focus on early-fatherhood depression, stress, dependency and reckless behaviour, a need also exists to look into the resilience that some of the young, poor fathers present. Scholars [5] also found that some of the young men in their study had strong social networks but needed further societal support. By contributing financially to the well-being of their children, young fathers find an affirmation of the self [5].

Issues of affirmation of the self for black men in South Africa cannot be divorced from colonial and apartheid history and its negative effects on experiences of fatherhood [6]. For example, the unequal distribution of resources across different racial groups and genders during the apartheid era

*Address correspondence to this author at the University of Johannesburg, Kingsway and University Rds, Auckland Park, South Africa;

Tel: 011559 3346; E-mail: Gracek@uj.ac.za presents contemporary South Africa with many challenges such as a high unemployment rate among black people. Recent statistics show that the unemployment rate stands at $35.6 \%$ for black people, $22.3 \%$ for coloureds, and $11.7 \%$ for Indians and Asians and only at 5.9\% for white people [7].

Socio-economic and political factors play a significant role in informing our understanding of fatherhood. In a developing country such as South Africa, the social and economic elements are important to consider when defining fatherhood [8]. Thus, the socio-historical context in which the definition is provided should be considered and should include issues of class, race and sexual orientation [9]. Some cultures allow fathers to be active in the day to day rearing of their children while others allow them to be passive and sometimes, absent. For example, the migrant labour system that was prevalent in apartheid South Africa compelled men to leave their homes to work in the mines [5]. Consequently, father's absence is acceptable in modern day South Africa. Another legacy of the migrant labour system is defining fatherhood predominantly as an act of providing financial support to the children [2]. Moreover, research demonstrates that compared to other groups, blacks are much more likely to be poorer and have pitiable access to healthcare, educational and psychosocial resources $[10,11]$.

Again, 'fatherhood' has undergone a variety of changes throughout South African history. During pre-colonial times, fathers were seen mainly as protectors and providers [12]. In these early contexts families and society in general feared and respected the father as the ultimate symbol of power [6]. Fathers had to spend time with their children to exercise authority over them. The father had also the responsibility to provide for the family and guide children by making important decisions on their behalf such as when to get married [6]. These roles were based on assumptions that fathers displayed particular qualities. These qualities include; protecting, supervising, defending, supporting, educating and shielding from harm [13]. However, research rightly 
maintains that fatherhood means different things in different contexts and the definitions are also time-bound [9].

For example, little knowledge exists about processes leading to the age that young men enter into fatherhood. In a New Zealand study with young men events that lead to fatherhood prior to the age of 26 were identified as significant $[14,15]$. The study revealed that most young fathers engaged in sexual activities early in their lives, most often commencing at 14 years of age. However, another scholar [14] contends the difficulty of distinguishing an age cohort that comprises of young fathers because of the complexities associated with the concept of fatherhood itself. Similar to the definitions of fatherhood, 'young-fatherhood' also depends on the socio-cultural context within its definition. The appropriate ages selected for transitions to different social roles influence these decisions. Examples include roles such as working, parenting and being marriage compatible [14].

From the evidence provided by Pears et al. [14] and Jaffe et al. [15], we argue that viewing men through an environmental focus best observe the transitions to earlyfatherhood. Individual internal and external assets require exploring as experiences differ from situation to situation [5]. In spite of the amount of resilience demonstrated by researchers [5], many studies show low academic performance and achievement, deviant behaviour at school, drug problems, and school dropout as the intrapersonal effects of early-fatherhood $[3,14,15]$.

Despite these obstacles, research shows that young fathers in South Africa hold a deep sense of responsibility towards their children [2]. However, in other cases, the young men simply show no interest and did not successfully transit from boyhood to manhood [16]. When parents highjack the father's responsibilities young fathers become 'almost absent' as a result of feelings of inadequacy, internal conflict and fractioned transitions [2, 17]. This study used the qualitative research approach in establishing how young fathers cope with early-fatherhood in township contexts where poverty and unemployment are a reality. A brief discussion of the methods used for collecting the data presented in the findings section of this article is captured below.

\section{METHOD}

This study adopted the interpretive, which maintains that it cannot objectively study reality but rather the political, economic and social context that participants live and interact in the interpretive paradigm. This is central in the conduct of this study and what this article intends to instantiate about young fathers from White City, Jabavu in Soweto. We used purposive and snowball sampling methods to recruit participants and chose it as a result of the already available knowledge of the population's characteristics [18]. We conducted in-depth interviews with six black men, between the ages of 18 and 25, and all were the residents of White City, Jabavu, Soweto. Two of the young men studied at universities, while others worked 'piece jobs' in either supermarkets or tuck shops in and around their community.

We recruited the initial participants from the Ipelegeng Youth Leadership Development Programme. Ipelegeng empowers young people through economic development programmes and arts and culture. It however, proved difficult to get all the participants from Ipelegeng, as only one participant from the youth centre agreed to participate in the study. The other two identified from Ipelegeng refused involvement as they did not regard themselves as young fathers. One denied the paternity of the child while the other one lost the baby when it was two months old. No one else from the youth centre fitted the selection criteria for the study; as a result we used the snowballing selection method. Snowballing refers to finding participants through referrals from other participants [18]. Furthermore, this type of sampling usually applies when the already sampled cases know others with similar characteristics. The one participant from Ipelegeng and another one used for piloting referred more participants to us during the course of the study.

The interviews lasted for over an hour after which we transcribed and analysed them using the thematic content analysis [19]. The analysis went beyond emerging themes and we discussed it in a way that indicates the connections and synthesis with already existing work on the topic [19]. We used pseudonyms to protect the identity and integrity of the participants. Furthermore, the University of the Witwatersrand non-medical ethics committee provided ethical clearance for this study.

\section{Research Site: Contextualizing White City, Jabavu, Soweto}

In qualitative research, understanding the social context in which people produce ideas and knowledge is important [18]. An apartheid separatist policy that sought to segregate black people and reserve the city for whites and mainly for economic activity gave birth to Soweto. As a consequence of the introduction of the White City area, a campaign to terminate the overcrowded, poverty-stricken and filthy squatter camps resulted in the splitting of residents of Jabavu across White City, Jabulani, Moletsane, Naledi, Senaoane and Dlamini [20].

The township received the name White City because of the concrete roofed 'elephant houses' that were initially painted white. The township is one of the most populated in Soweto with more than two families at times occupying one yard or space ordinarily allocated for only one house. The houses are single, free standing structures, divided into three parts shared by three families in either two or three rooms and have electricity and clean running water $[20,21]$. As a low-income community, working adults in White City, Jabavu hold various positions in the nearby city and the informal sector is growing. About $40 \%$ of the households do not have any means of generating income, while a daunting $60 \%$ of the adult population is unemployed [21]. This socioeconomic scenario is a reality of many other townships where the majority of black people reside.

\section{Interviewee Dynamics and Conceptions of Young Fatherhood}

The first author in this article undertook the fieldwork that informs this paper. She is a young black woman from a neighbouring township, who at the time of the study, was registered for a post graduate degree in Social Work. Although young and black, like the participants, the gender of the young woman influenced her role as a researcher in 
many interesting ways particularly with regards to the understanding of young fathers.

During the course of this study, the fieldworker developed a peculiar interest in the day to day discourses of the community about early-fatherhood. She found herself interested in public discourse on young fatherhood wherever she went. For example, she captured in her field diary, a conversation that she heard between an elderly woman and a pregnant school girl in a taxi. The woman was asking the girl if the man who had impregnated her was still around "as after getting what they want, these young boys run away" (Field notes, 20 July 2012). Although the girl said the father is there for her and is supportive, the woman warned her by suggesting that he would change for the worst and thus encouraged the girl to be ready for single-parenthood. This type of talk captures societal reality where even though, "Africans are as pronuptial as Whites, both in a desire to marry, and in the perceived advantages of marriage" [22], more African women are unmarried and are raising children in context of father absence. On the other hand, research on fatherhood and child support in Johannesburg [23] found that even though the idea of the absent uncaring father defined public discourses of fatherhood, the situation of fathers was more complex.

In agreement with Khunou's [23] idea of multiple experiences of fatherhood, the fieldworker captured in her field diary, cases where other members of the community were compassionate and sympathised with the young fathers. An entry of the $2^{\text {nd }}$ of August indicated that before an interview with one of the participants, his sister said: "at least their generation has become more responsible and is more caring" (Field notes, 2 August 2012). Young fathers are not necessarily uncaring and passive, but they find it difficult to support their children in all possible ways [5]. These contradictions reflect exactly what Morrell [24] meant when he argued that men cannot be clustered into one rigid category.

\section{FINDINGS AND DISCUSSION}

We collected data for this article from six men, all fathers to one child each, and only one experienced denied access to his child. The first theme discussed in this section is on how fathers speak about love and provision as significant markers of young fatherhood. Secondly, the section discusses how the observation of what one participant calls 'good' and 'bad' fathers' influences learning and therefore how young fathers make meaning of fatherhood and what is expected from them. The third section looks at how denied access and the distance experienced by young fathers influences experiences of less involved fathering. The final section deals with the consequences of less involved fathering and how it plays a role in signifying the notion of father as a provider in the lives of the young fathers. The themes discussed in this section illustrate the complexities in how the young fathers understand themselves and how others, in turn, understand them in their environment.

\section{Love and Provision as Significant Conception of Early- Fatherhood}

In exploring the meanings attached to fatherhood, we asked participants to reflect on their own understanding of the role. A father must be able to provide financially for the child, guide the child and offer emotional support, featured as the most prominent ideas. The provider's role is very prominent in how we understand fatherhood. As indicated in the literature, traditionally, conceptions of fatherhood were directly linked to the idea of father as the provider [23]. We found the same to be true in other studies of father absence. For Tshepo, a self-supporting 24 year old young man, who worked at the airport and had a two year old son at the time of the interview, fatherhood meant the following:

\section{" a father must be a good example to his child and be a good person. He must always be there for the child, financially, emotionally and be there physically" (interview, Tshepo, 17 August 2012).}

It is interesting how Tshepo spoke of these traits even though he is not allowed contact with his child. He claimed that the maternal family refused him contact and accused him of denying the paternity of the child. These issues are highly contentious in the South African fatherhood context. Literature indicates that in cases of denied paternity, conflict surrounds the role of the father [23]. In her paper on young fatherhood and child support, Khunou [16] also indicates that the maternal family plays an important role in encouraging or discouraging active fatherhood.

From Themba's perspective, provision and love are significant in defining fatherhood. Themba loved his five year old daughter dearly and perceived fatherhood differently; even though it was difficult accepting the pregnancy of his ex-girlfriend. Themba now adores his child and says that she completes him. He was 23 years old and in the third year of university, studying towards a B.com degree at the time of the interview. Themba said the following about what it meant for him to be a father:

"you know, a father must be able to interact
with the child, be there through thick and thin.
Money is also important; children are
expensive so as a father you must ensure that
there are nappies, milk and everything. But
ultimately, the love is the most important
factor because money won't raise a child"
(Interview, Themba, 29 August 2012).

Themba's explanation also highlights the fear that accompanies the entry into fatherhood. This also suggests the constant negotiation of the idea of fatherhood and that comes with expectations and role changes. He also mentions the importance of money and speaks of a "child as expensive", thus foregrounding the 'traditional' notion that a father is a provider. In Khunou's [16] discussion of money and manhood, it was not acceptable when a woman took over the financial responsibility in the relationship. Similarly, Themba carries the entire financial burden in raising the child; he sees it as his responsibility and not that of the mother. This, then, makes his statements contradictory - "money will not raise a child" - and does not fit in with his signifying the provider role. Themba explains the prevalence of the element of love; he puts it as a cherry on top in that once you have dealt with the money in the provider role the father must not forget to love. In the case of many South African men, the unemployment of the father challenges the 
idea of a father as a provider [23]. In 2012, the unemployment rate of men in South Africa stood at $25.6 \%$ [7].

Neo, a 24 year old father of a two year old boy, at the time of the interview also confirmed financial provision as an important element of fatherhood, even though he made some reference to nurturing and caring. He said:

"He must provide financially. But also not just someone who sets rules for his child but is also his friend. And when the child gets old you must know that you are a brother to that child. And your child shouldn't feel intimidated by you" (interview, Neo, 28 July 2012).

Neo's conception of fatherhood seems more like a redefinition of what he once understood about the term. He argues that fatherhood should not only be about exercising power over your children, but guiding them. This speaks directly to Lesejane's [6] explanation of a definition of fatherhood in the patriarchal context. He argues that in patriarchy, a father is there to make decisions for the children and exercise authority over their lives. Fatherhood is also associated with great responsibility. Swartz et al. [5] and Khunou [12] argue that young fathers must take fatherhood seriously and not as a channel to prove their masculinity. For Sipho, an unemployed 23 year old at the time of the interview, fatherhood meant:

“...mmm... According to me? Is someone who is able to take his responsibility? Besides money I can mention love do you get me?"

(Interview, Sipho, 2 August 2012)

Consistent with the existing literature, the present study shows how meanings of fatherhood still signify the longstanding paradigm of fathers as providers [2, 12]. However, given the growing economic challenges and high unemployment, more and more fathers are not working and can thus expand their roles to nurture and care. Even though literature also suggests that young fathers expressed a deep sense of responsibility towards their children [5], this study indicates that unemployment and the hegemony of the provider role act as barriers towards the fulfilment of fatherhood aspirations of love and care that some young fathers hold.

\section{Observation of 'Good' and 'Bad' Fathers: How Social Context Influence Young Fathers Conceptions of Fatherhood}

While exploring influencing factors of the young men's conceptions of fatherhood, it became evident that the social context within which they grew up played a significant role in shaping these ideas. The participants referred to their own observations of fathers around them as well as their own fathers, highlighting that fatherhood is a learned social role. Consequently, understanding fatherhood must include socioeconomic factors, history, and culture $[5,8]$. Neo's ideas of being a good father were influenced by his observations in his community. His conception reiterates his idea of a father as guide; he shared this idea in the following way:

"I can say growing up I have seen fathers...well some fathers do all this, even my own father. In families where there are no

\begin{abstract}
fathers I could see that there was something missing, the children got out of hand and some were very poor so I made up my mind that no this is what a real father should be doing" (interview, Neo, 28 July 2012).
\end{abstract}

Neo's argument highlights that he had no initiation into fatherhood, but drew from his own experiences to know what roles fathers play. The significance in his earlier argument that a father should guide his children shows that for him, children get out of control in the absence of a father. Studies of father's absence signify the role of the father as guide. Neo's conception links fatherhood with order and direction. Although Neo's notions of the father as guide holds some truth other research cautions that single mothers do not necessarily raise naturally deviant children [25].

Learning influences how the young fathers conceive their role as fathers. Tshepo learned about fatherhood through observation of his social context, this is what he said:

"ja it's out there as well, people that are close to me, and as I was growing up there were fathers around me that I saw. So I also learned from them" (interview, Tshepo, 17 August 2012).

Tshepo attributed his understanding of fatherhood to what he saw around him. This added to his frustration of not interacting with his child. He mentioned that a father should set a good example but his denied access to his child takes this away from him. On the other hand, Themba's experiences were different, he learnt from having what he called 'good' and 'bad' uncles'. Uncles, according to Ratele [26], are significant as social fathers. Themba shared his experiences in the following way:

"my father raised me well so I know that I owe it to my children to do the same. I would also say that I could see with my uncles (laughs) the good ones, they really loved their children and did everything for them. But the bad ones were always in trouble, I remember my aunt dropping her child on the 'stoep' because my uncle didn't send money...I knew then that I wouldn't want to raise my children like that" (interview, Themba, 29 August 2012).

Themba's witnessing makes a distinction between the good and the bad fathers and draws memories of how the bad ones affected the children. This helped him to distinguish between desirable and undesirable behaviours. Literature also shows that because masculinities are learned, this indicates that social roles, including fatherhood, emerge from the attained masculine identity [27]. Hence, Themba distinguished between responsible and irresponsible masculinity and chose one based on the perceived consequences. This, then, highlights the significance of the relationship between the person and the environment and how both become important in forging parenting roles for young fathers.

\section{Denied Access, Distance from the Child and Implications for Young Fathers Roles}

Most young fathers are unmarried and do not reside with their children; as a result, this distance often impedes their 
ability to play the carer-nurturer role [5]. The mother then remains the primary caregiver while the father just shares these roles. Cultural expectations create another obstacle for young fathers in performing their fatherhood roles. The maternal family often rejects and despises the young father due to the negative meanings of teenage pregnancy for their daughters [23]. This ultimately prevents any form of contact with the child. For example, at the time of the interview, Tshepo experienced refusal of interaction with his child and only had pictures of him on his phone. He expressed this separation thus:

\section{"Her family doesn't want me and she likes bad mouthing me to them, telling them that I'm a player and a bad boy. That has hindered me from seeing my child. And they are insisting that I denied the paternity of the child" (interview, Tshepo, 17 August 2012).}

Denied access to the child for non-resident young fathers leads to serious challenges for these fathers. Mothers also quote this factor when they experience conflict with the fathers; the child is caught in between. For Kgomotso the following indicates how he spent time with his child:

"ja he lives with his mom, during weekends there are some things that I do to get some money. But during the week I make sure that I go see him. He is very young so I can't play with him. I just hold him and kiss him...ja" (interview, Kgomotso, 20 July 2012).

Mothers, deemed as primary caregivers, bear the responsibility of rearing their children. Fathers, and especially unmarried young fathers, are expected to visit their children and do not live with them. Hence, despite needing prolonged interaction, young fathers cannot attain it because of their predetermined role in child rearing [2]. Sipho's experiences were somewhat different; although he did not live with his child he interacted with him daily. However, the decision to do so was left entirely up to him and was not seen as a prerequisite, Sipho said:

"Almost each and every day, sometimes he spends some time at my house, if not I go to the mother's house" (Sipho, interview, 2 August 2012).

Although distance is not a challenge for Sipho, and therefore he can be present whilst not staying with his child, this is not the norm for other young fathers. For example, Karabo could not interact frequently with his child due to distance, he said that:

"It's hard spending time with him because they live far, but I ensure that I see him at least twice in a week, depending on whether I'm working or not" (interview, Karabo, 22 June 2012).

Literature indicates that young fathers find having long and meaningful interactions difficult because of the geographical distance between them [2]. This then results in frustrations for the young men as they cannot fully enact the nurturing and caring roles that they desire. Although there is little information available about the effects of young fathers' involvement in the rearing practices of their children, literature highlights a number of benefits that result in frequent and intense interactions between fathers and their children. These include: cognitive independence; improved academic achievement; positive socio-emotional development; positive peer relations; and career success and a higher education expectation $[28,29]$. These are however only possible when the father holds healthy notions of what it means to be a man and a father.

\section{Fulfilling the Provider Role: Young Fatherhood not only negative for Young Fathers}

For this study not all participants had left school or had low paying jobs. Instead, early-fatherhood influenced some of the young men to work harder in order to provide for their children and set good examples for them. This is not fully consistent with literature that suggests that young fathers are usually from poor backgrounds and therefore do not provide for their children [17].

For example, Neo worked as a lecturer at the local college and studied for a B.Com Marketing degree part time. He shared that he worked hard so that he can provide his son with the life that he never had. However, for Kgomotso the situation was different, he left school in order for him to provide for his child, this is what he said about his experiences:

"Actually I didn't finish school, I stopped at
grade 11, that's where I stopped so that I can
go to college, at high school I should have
finished it last year, but I couldn't finish
because my girlfriend fell pregnant. I couldn't
continue, I mean she had to drop out too so I
joined her since no one could be there to
provide for the baby" (interview, Kgomotso,
20 July 2012).

The above experience is consistent with research that suggests that to fulfil the provider role; many young fathers leave school to find employment to support their children [17]. Kgomotso's job basically only puts food on the table since it does not pay much. The following indicates his sense of the job;

"My mom has a tuck-shop at Randfontein, so I go there and help her out. She doesn't pay me much, it only all depends on how business was on that day. yea like that" (interview, Kgomotso, 20 July 2012).

Working for so little pay, seemed like the only option for Kgomotso to fulfil the provider role. Again the fact that he left school might in the long run have negative consequences for his child, especially given the high unemployment challenges in South Africa. Although Kgomotso's case illustrates that young fathers might need to leave school to find work, this is not true for all young fathers. For example, Themba comes from a family of four; his mother was an educator and his father a doctor at a public hospital in Soweto. He was well groomed, well dressed and his parents sponsored his tertiary studies. He became a father in grade 12 and even though he took a break from studying, he enrolled for a B.Com degree, completing his final year at the time of the interview. Therefore, Neo and Themba fall outside the category of risk of low income jobs or 
unemployment at the age of 30 as suggested in some literature [30].

Although young fathers deem both nurturing and material provision important, the need to provide financially often overrides caring as this role is associates with manhood and adulthood. This confirms what other studies show; Madhaven et al. [31] argues that fatherhood largely depends on access to resources. Khunou [12] also echoes this when she suggests that it is often middle class men who have no trouble enacting both the provider and carer role and which poorer fathers only aspire to.

\section{CONCLUSION}

Understanding early-fatherhood without unravelling the very factors that complicate it is a challenge. These factors are found in how the young fathers comprehend their experiences and the social, cultural, economic and political factors specific to time and space that inform those experiences. This article argues that full comprehension of early-fatherhood is impossible without an understanding of how the person interacts with their environment and vice versa.

The young men in this study clearly illustrated how they acquired their assumptions of what fatherhood means through general interactions in their community as well as the past experiences with other men in their community and families. This in a nutshell shows, how and what was available to the young fathers in their particular context, what helped shaping their beliefs and consequently how they enact the fatherhood role. Unemployment also impacts on the young fathers' ability to fulfil the provider role, however, while unemployment remains one of the pressing issues for young fathers, dropping out of school or not pursuing tertiary education lessens their chances of acquiring a stable wellpaying job.

We hope that through this article, policy makers and programme developers will realise the challenges faced by young black fathers in White City, Jabavu and will formulate strategies tailored to suit their specific needs. Furthermore, we wish to emphasise the significance of contextual influences on the experiences of young fatherhood.

\section{ABOUT THE AUTHORS}

Ms. Naledi Selebano is a research intern at the CGE.

Prof. Grace Khunou is Associate Professor in the Sociology Department at the University of Johannesburg.

\section{CONFLICT OF INTEREST}

The authors confirm that this article content has no conflict of interest.

\section{ACKNOWLEDGEMENTS}

We would like to acknowledge the research participants for giving their time and sharing their stories.

\section{REFERENCES}

[1] Larsen MV. Pupil and pregnant: young mothers in South Africa, 2011. [Cited 2012]. Available from: http://www.capechameleon. co.za/printed-version/issue-10/cover-story/
[2] Panday S, Makiwane M, Rancho C, Letsoalo T. Teenage pregnancy in South Africa: with a specific focus to school-going learners. South Africa: National Department of Education 2009.

[3] Thornberry TP, Wei ER, Stouthamer-Loeber M, Van Dyke J. Teenage fatherhood and delinquent behaviour. United States of America: Office of Juvenile Justice and Delinquency Prevention 2000.

[4] Smith PJD. Social work interventions for unmarried teenage fathers. Doctoral [dissertation]. South Africa: University of Stellenbosch 2006.

[5] Swartz S, Bhana A. Teenage Tata: voices of young fathers in South Africa. Cape Town, South Africa: HSRC Press 2009.

[6] Lesejane D. Fatherhood from an African cultural perspective. In: Richter L, Morell R, Eds. Baba: Men and Fatherhood in South Africa. Cape Town: HSRC Press 2006.

[7] Statistics South Africa. Mid-year population estimates 2012. [Cited 2012]. Available from: www.statssa.gov.za

[8] Morrell R. Fathers, fatherhood and masculinity in South Africa. In: Ritchter L, Morell R, Eds. Baba: Men and Fatherhood in South Africa. Cape Town: HSRC Press 2006.

[9] Peters HE, Peterson GW, Stenmetz SK, Day RD. Fatherhood: research, interventions and policies. New York: The Haworth Press Inc 2000.

[10] Coovadia H, Jewkes P, Sanders BD, McIntyre D. The health and health system of South Africa: Historical roots of current public health challenges. Lancet 2009; 374: 817-34.

[11] Burns JK. The mental health gap in South Africa -A human rights issue. Equal Rights Rev 2011; 6: 99-113.

[12] Khunou G. Fathers don't stand a chance: experiences of custody, access and maintenance. In: Ritchter L, Morell R, Eds. Baba: Men and Fatherhood in South Africa. Cape Town: HSRC Press 2006 b.

[13] Bradley EA. Fatherhood: the role of a father. USA: Tate Publishing \& Enterprises, CCC 2009.

[14] Pears KE, Pierce SL, Kim, HK, et al. The timing of entry into fatherhood in young, at risk men. J Marriage Family 2005; 62: 42947.

[15] Jaffee SR, Caspi A, Moffitt TE, et al. Predicting early parenthood and whether young fathers live with their children: Prospective findings and policy reconsiderations. J Child Psychol Psychiat 2001; 42: 803-15.

[16] Khunou G. Paying your way and playing with the girls: township men and meaning of manhood. South Afr Labour Bull 2009; 35: 48-50.

[17] Coley RL, Chasedale P. Adolescent pregnancy and parenthood: recent evidence and future directions. Am Psychologists 1998; 53: 152-66.

[18] Babbie E, Mouton J. The practice of social research. South Africa: Oxford University Press 2001.

[19] Bazeley P. Qualitative Data Analysis: Practical Strategies. London: Sage Publications 2013.

[20] Bonnet PL, Segal C. Soweto-a history. Cape Town: Maskew Miller Longmann 1998.

[21] Palmer Development Group. Soweto: retail demand analysis. Johannesburg: Market decisions 2004.

[22] Posel D, Rudwick S. Attitudes to marriage, cohabitation and nonmarital childbirth in South Africa. A paper presented at the Microeconomic Analysis of South Africa Data Conference, November 2012.

[23] Khunou G. Maintenance and changing masculinities as sources of conflict in contemporary Johannesburg. Doctoral [thesis]. South Africa: University of the Witwatersrand 2006a.

[24] Morrell R. Changing Men in Southern Africa. Pietermaritzburg: Natal University Press 2001

[25] Langa M. Adolescent boys' talk about absent fathers. J Psychol Africa 2010; 20: 519-26.

[26] Mkhize N. African tradition and the social, economic and moral dimension of fatherhood. In: Richter L, Morrell R. Eds. Baba: Men and Fatherhood in South Africa. Cape Town: HSRC Press 2006.

[27] Ratele K. Masculinities, maleness and (illusive) pleasure. South Africa: WIPE Programme, Institute of Social and Health Sciences, University of South Africa 2008.

[28] Allen S, Daly K. The effects of father involvement: an update research summary of the evidence [Unpublished manuscript 2007].

[29] Hettler JB. Young fathers' experiences: the process of becoming. Masters [dissertation]. Alberta: University of Calgary 2000. 
[30] Berrington A, Ingham R, Stevenson J. Consequences of Teenage Parenthood: Pathways which minimise the long term negative impacts of teenage childbearing. University of Southampton: SRI 2002.
[31] Madhavan S, Roy K. Securing fatherhood through kin work: a comparison of black low income fathers and families in South Africa and the United States. J Family Stud 2012; 33(6): 801-22.

(C) Selebano and Khunou; Licensee Bentham Open.

This is an open access article licensed under the terms of the Creative Commons Attribution Non-Commercial License (http://creativecommons.org/licenses/ by-nc/3.0/) which permits unrestricted, non-commercial use, distribution and reproduction in any medium, provided the work is properly cited. 